\title{
An Effective Employee Retention Policies as a Way to Boost Organizational Performance
}

\author{
Ibrahim Abdulai Sawaneh ${ }^{1, ~ *, ~ F a t m a t a ~ K a n k o ~ K a m a r a ~}{ }^{2}$ \\ ${ }^{1}$ Department of Computer Science, Ernest Bai Koroma University of Science and Technology, Magburaka, Sierra Leone \\ ${ }^{2}$ Head of Career Department, Sierra Leone Peacekeeping and Law Enforcement Academy (SILEA), Hastings Police Training School, \\ Hastings, Sierra Leone
}

Email address:

ciddiisawaneh@hotmail.com (I. A. Sawaneh)

${ }^{*}$ Corresponding author

\section{To cite this article:}

Ibrahim Abdulai Sawaneh, Fatmata Kanko Kamara. An Effective Employee Retention Policies as a Way to Boost Organizational Performance. Journal of Human Resource Management. Vol. 7, No. 2, 2019, pp. 41-48. doi: 10.11648/j.jhrm.20190702.12

Received: June 16, 2019; Accepted: July 3, 2019; Published: July 13, 2019

\begin{abstract}
Several organizations in developing nations overlooked the most important elements determining employee retention as a strategy in achieving organizational outputs, making them to become victims of industry competition locally and internationally. The study was conducted to examine the factors that undermine employee retention in tertiary educational institutions in Sierra Leone. Good employee retention policies are crucial to the development of organizational success, as many organization view retaining talented and skillful employee as the basic foundation for reducing cost, and achieving organizational blueprint. Keeping the most talented employees will be the most engaged employees that know the cornerstone of the organization's policies and operations. They are the main pillars of organization and to some extent, are willing to sacrifice themselves for the success of the organization. They worked tirelessly to attain organizational objectives. Therefore, much attention must be giving to them, more especially considering the factors that will motivate them to do their jobs excellently. They should be treated fairly and must be evaluated on the metrics that define employee retention strategies for organizational success. This is because the organization needs good employees for its day-to-day operations, and good employees make organization successful. Most organizations ensure that they retain the best employees by all means. Losing talented employee is catastrophic in terms of cost and others, making the cost to replace such employee quadrupling their salaries about $300 \%$. Noting that the organization must have spent substantial amount of money on them, such as training, mentorship, scholarship, and other motivational schemes.
\end{abstract}

Keywords: Employee Retention, Reward, Compensation, Employee Retention

\section{Introduction}

Sound employee retention policies are fundamental to the development and success of organizational goals and objectives in the $21^{\text {st }}$ century business competitive world. The improvement in technological innovations, changes in global economics, trade agreements, trade war, the rise of protectionism, the rise of more business entities and others are obviously having negative effects on employee and employer relationships, thus resulting to a high employee turnovers and subsequently affecting employee retention in an organization. It is evident that, outstanding employees may leave an organization when they become dissatisfied, political interference, racism, regionalism and tribalism (particularly in Africa), lower salary and retaining such distressed employees will be met with other challenges as well [1]. Cappelli indicated that for a well-functioning of employee retention, several important factors must be considered for organizational success [2]. The results will have a direct outcome on employee retention such as: career developments, working ecosystem and a balance work-life. Research has suggested that people normally stayed with a particular organization when they have a sense of pride, prompting them to work to their fullest potential [3]. The reasons to stay with a particular organization include: harmonized working ecosystem, merited reward system, growth and development strategies, and balance work-life. 
Several studies have indicated that most organizations are successful as a result of placing values on their employees, and most importantly investing in their employees' capacity building [4, 5]. An organization view retaining talented employee as a fundamental principle for achieving competitive advantage amongst others [6]. The findings done by Aliya and Fariduddin in 2003, hypothetically suggested the factors leading to a positive attitude and that leading to a negative attitudes are different [7]. Most private learning institutions in Sierra Leone over the years have failed to retain their most talented and valuable employees. According to Kehr, the inherent retention strategies is spontaneous, sensitive and agreeable behavior classified into three elements; power, achievement and affiliation [8]. In this scenario, power refers to the supremacy and recognition, achievement refers to personal standards of excellence that are to be fulfilled or over-fulfilled, and affiliation refers to the social relationships established. Implicit and explicit retention elements narrate the diverse characteristics of a person, as both are key determinants behavior.

Sierra Leonean educational sector has become competitive following a plan by the "New Direction Government" to increase the number of both private and public universities, polytechnics and colleges across the country. The government of Sierra Leone have proposed to establish university in Kono, Kenema, and also transformed the Milton Margai College of Education and Technology to a university status. Further plan are on the verge to transform the Freetown Teachers College (FTC) and Government Technical Institute (GTI) into one Freetown Polytechnic by 2020. Also, massive scholarship schemes have been implemented by the current administration in order to boost the student population for public universities in Sierra Leone. This requires private colleges and universities to have effective employee retention policies in place, which will motivate talented staff in all sectors ranging from science, technology, management, engineering, arts, education, administration, finance, and other relevant demanding areas, and also support staff who ensure the institutions dream is made possible. Furthermore, the educated and qualified staff recycle from one institution to another for better employment terms and balance work-life. Also, due to poor retention policies, dedicated and skillful employees have being wrongly terminated due to power struggle by certain senior management within such administrations. As such, human capital is viewed to be a key competitive instrument in the educational sector that calls for appropriate managerial standards to ensure sustained competitive advantage.

For instance, the Institute of Advanced Management and Technology (IAMTECH) employees over the last decade have created a unique organizational culture. Most of the courses offered are professional courses that meet the need of the present societal problems. Therefore, students turnover have been good for the institution for the last five years. Unfortunately, such professional courses are on a strategic rollout at IAMTECH, and planned to be incorporated into public universities. Such undergraduate courses include:
Logistic and Procurement Management, Human Resource Management, Mining Management, Petroleum Management, and others. In the public universities, courses offered are more less the same, making it hard to compete on courses basis. This is an added competitive advantage for private universities, as the public are always pleased with the quality services offered meeting the global trend. For a University to offer demanding courses, it is key that they recruit, train, develop and retain valuable teaching staff and talented administrators.

\section{Motivation}

The authors were motivated due to the massive loss of talented and hardworking staff from 2017 to 2019, and about 30 staff were either terminated or resigned in few selected private educational institutions. Therefore the research suggest an effective strategies on how to circumvent loss of organization's knowledgeable workforce. The research further helps organization to retain valuable employees for the benefit of long success of the organization.

\section{Research Objective}

To examine best practice for employee retention policies and strategies in an educational institutions, and possibly recommend/suggest to retain most valuable employees.

\section{Scope of the Research}

The study was conducted as a result of the versatile knowledge by the authors in regards to educational institutions in Sierra Leone. The authors have worked in various capacities in several higher institutions of learning from 2009 to 2019 across the country. Therefore, the study focuses on the major areas of employee retention strategies. The research suggest an effective retention strategies be implemented as there are no such strategies in place, thereby deterring the progress of most institutions of higher learning in the country. It is also helpful, as it will draw the attention of top management to draft effective policies and strategies regarding employee retention process, and also create a HR department for recruiting, promotion, and termination staff who play less role in the organization's development.

\section{Related Literature}

The support from immediate superior acts as a major contributing factor in employee retention strategy. The trustworthiness and attachment with the organization will be greater where the supervisor and supervisee build affirmative and resilient relationship, enhancing the organization to maintain such employees on a longer term. This is attributed to the fact that employees' perception about their workplace is vastly motivated by their relationship and bonding with the supervisor [9]. Fluent and transparent communications between employees and their bosses encourage them to 
perform well in an organization [10]. This cordial relationship between supervisors and supervisees enhance the development of staff competencies and innovative skills among employees. This will prompt individual employee assurance to stay longer with such organization [11].

Lack of transparency with the immediate boss might result into additional pressure on the employee, and further cause stress among employees that will lead to a decline in efficiency and performance. Ultimately, it will cause reluctance from an employee to work with such supervisor [12]. Furthermore, to increase organizational success and competency, it is key to have a compassionate and inspiring relationship between a supervisor and a subordinate [13]. Noting that human capital is an integral part in developing an organization. "Human Capital stays where it is well appreciated". It can only be attracted and not driven. Walter Wriston, Former chairman of Citibank stated in his address. It is evident that committed employee plays vital role in the development and sustainability of an organization in modern times. Talented and skillful employees invent innovative ideas that subsequently determine the survival of an organization in this competitive globalized economy. Most dissatisfied or disgruntled employees upon leaving an organization, sometimes have tangible evidence such as organizational secrets, culture, knowledge, experience, values, audio recordings and sensitive documents that may have negative effects if disclosed to the public. It may also signal wrong public perception about the organization's operations.

\section{Methodology}

The study is descriptive and only uses secondary data, and the author's long acquaintance with educational institution's operation in the country. The secondary data include: textbooks, internet, academic articles, and conference papers.

\section{Causes and Influencing Factors Turnover}

The costs of losing talented employees are actually devastating, causing over $300 \%$ of their salary to replace them! Normally, it is as a result of job dissatisfaction for individual employee in the work environment. However, being dissatisfied in a work environment is not the only reason for leaving an organization. When employees possess skills that are in demand, they are likely to be tempted by a high salary, more benefits or better potential for career development. Consequently, it is sometimes necessary to adequately understand and identify the difference between employees who are unsatisfied, leaving the job and those who quit for other reasons. There is a variety of causes and determining factors that result in employees' leaving a particular organization, and some of the determining factors include:

\subsection{Managerial Factors}

High employee turnover is caused by the instability in the management of an organization. Employees absolutely inspire job satisfaction level, thereby affecting employee retention turnover directly or indirectly. Employees feel satisfied about their work and stay longer in their positions to get them involved in the organizational decision making process. For this reason, decision makers should understand issues that influence the workplace [14]. One argument put forward is that a high turnover of labour possibly implies poor staffing and selection policy, poor supervisory system, weak grievance procedure and lack of motivation. All these issues can result into high labour turnover in the sense where there have been no appropriate managerial guidelines on personnel issues and, thus, employees decide to leave the job [15].

\subsection{Working Environment}

If working environment is low-graded due to lack of all the basic facilities such as proper lighting, working in a space with some natural light, ventilation, air conditioning system, open space, restroom, equipped laboratory, furnished staff common room, closed office space for heads of department, deans, directors, furniture, safety equipment while discharging duties, drinking water and refreshment, workers will not be able to face difficult situation for too long [16]. Besides, a bad supervisor creates a hostile working ecosystem, thereby prompting highly qualified and talented employees to leave the job.

\subsection{Pay}

Pay is something given in exchange for services rendered in an organization [17]. It has played a vital part in retaining and rewarding high quality human resources. Low salary is viewed as one key factor for employee leaving a particular job. When employees' receive lower salary and insufficient financial rewards, they tend to stay no longer with the organization [18]. It is often said that job dissatisfaction is the major cause of poor pay scale procedure, leading employees to leave the job. A good illustration of this is that a new employee may guess why the person next to him gets a high salary for what is supposed to be the similar job [19]. A common opinion is that good pay can be a strong determinant of job satisfaction that leads to achieve higher productivity in the organization.

\subsection{Fringe Benefit}

A fringe benefit is an additional or supplementing incentive assigned to employee's salary or wage; such as official vehicle, apartment, medical allowance and others for managerial entitlement, which has increases effective performance and help maintain employee retention [20]. It is viewed that such benefit planning is a key to human resource planning practice, in relation to the colossal expenditures and financial resources appropriated for the future [21]. At the 
managerial level, a fringe benefit is essential for attracting, retaining and motivating employees who may continue to work for the organizational success. One reason for this is that fringe benefits play a significant function to persuade individual's interest working in a particular organization. In fact, numerous organizations provide fringe benefits, incentives and recognize employee's performance, directing a device of motivation [22].

\subsection{Career Promotion}

In wide terms, reward program demonstrates the broaden theory of compensation strategy which is described as a "deliberate utilization of the pay systems as an essential integrating mechanism through which the efforts of various subunits or individuals are directed towards the achievement of an organization's strategic objectives" [23]. The best way of promoting and motivating employees would be a combination of pay, promotion, bonus and other kinds of rewards to achieve organizational performance [24]. The reason behind is that lack of promotion and ordinary work responsibilities considerably can lead to the intention of turnover [25]. To an extent, employees consider leaving the organization due to the ineffective performance assessment and perceptions of job unfairness [21]. By implementing "job enrichment" programs, organization would be capable of retaining talented employee and to provide opportunities for better career development [26].

\subsection{Job Fit}

According to Campion, Selection process is related to the fit between the candidate and the job [27]. O'Reilly et al in 1991 argued that job satisfaction levels will go up if there is a good fit between qualities of the applicants and the job [28]. Therefore, it is essential to identity what the candidate wishes for and what the organization requires. Organizations will increase the productivity if they recruit the suitable employees and take necessary measures to increase job satisfaction. On the other hand, turnover will not be minimized until employees are not satisfied with the job. As a result, management needs to deal with the pressing issue of employee's turnover and job satisfaction. Thompson et al. [29] state that "A happy worker is a productive worker".

\subsection{Clear Job Expectation}

If organizations cannot fulfill the highest capacity of personal job demand, employees may have a feeling of job dissatisfaction that result in turnover intention. One of the major causes of employee's turnover is that employees depart the organization, while newly hired employees do not get their job expectations. Secondly, some employees are rather unlikely to be in a situation to tolerate few managers or supervisors and, hence, they come to a decision leaving their positions. As a consequence, it is more imperative for an organization to understand employee's job anticipation and, side by side, take necessary steps to fulfill their needs.

\subsection{Perceived Alternative Employment Opportunity}

Employees leave the organization if there is a possibility to get an alternative work [30]. However, it is seeing as an unmanageable issue, depending on the external environmental factors, such as job availability and the rate of unemployment. A study conducted by Carsten and Spector [31] found considerable relationship between job availability and voluntary turnover. To be more precise, perceived alternative opportunity may also be exaggerated by the market condition and educational background. We observe this when personnel with higher educational background is more qualified and experienced so that they can perceive alternative job opportunity [32]. In other words, higher educated employees have more chance of upgrading their positions in comparison with less educated employees and are likely to consider their qualification as a competitive advantage.

\subsection{Influence of Co-workers}

In 2002, a study carried out by Martin and Martin [33], of 477 workers in 15 companies investigates the reasons why employees are intended to quit the job. Furthermore, a job change acts as a form of social burden or rationalization on employees while co-workers intend to leave their positions.

\section{Sound Strategies to Minimize Employee Turnover}

It is unwaveringly crucial to stay put the potential employees in the organization. Managers need to arrange employees' capacity training and learning programs that focus on key employee satisfiers and dissatisfiers so that they can make a well balanced job design and control system to retain talented employees in the organizations [34]. One of the major causes of job dissatisfaction is poor income, which may result in employees leaving the organization. Therefore, it is more essential to build up a sound retention plans and have a good relationship between managers and subordinates in any organization.

\subsection{Recruiting Suitable Employees}

According to Hulin et al. [35], staffing is designed at providing a pool of latent human resources from which organization can select the most suitable qualified employees on the basis of job condition. Hence, if the organizations try to minimize the rate of employee turnover, it is required to ensure that the suitable applicants have considered for recruitment and selection in the job. Recruitment is the process of attracting prospective candidates so that they will possibly contribute to the organization [36]. It becomes noticeable that sound strategies are needed to draw an attention to the employees and motivate them to stay put in the organization. However, organizations should have the ability to identify the right, qualified and experienced employees and thus, this will lead to achieve the business 
goals. What this means is, businesses would have letdown or diminutive growth unless they recruit skilled workforce [37].

\subsection{Retaining Valuable Employees}

Mobley [38], describes the responsibility of an organization to retain potential employees because they will probably contribute to the attainment of the organizational goals. The immediate cause of this, retaining the best employees for an employer could have a competitive advantage as compared to others. HR management should take steps for an appropriate employee assessment so that the most suitable candidates are employed. "The quality of an organization's people is always an essential ingredient of successful strategy execution - knowledgeable, engaged employees are a company's best source of creative ideas for the nuts-and-bolts operating improvements that lead to operating excellence" [39]. Organizations may employ "next of kin" to an applicants as the best way to motivate and retain the top talent. Despite the fact of family reasons, this approach will minimize the family reasons to quit the organization, particularly, in the technical work.

\subsection{Effective Leadership}

It is fairly likely that employees will not stay in their jobs because of lack of support from managers [40]. Many researchers are of the view that poor supervision is one of the leading factors of employee turnover and, hence, it is vital for an organization to coach its managers in order to improve their organizational and leadership skills [41]. It comes to appear that employees do not have to be friends with their immediate supervisor, but requires to co-exist a mutual relationship with their immediate supervisor. However, one argument put forward by management experts is that the immediate boss needs to give direction and feedback, have regular meetings, respect their subordinates, and work with them in a friendly environment.

HR managers often develop new ideas to improve employee retention, but HR experts believe that one of the most important retention tools is being a leader instead of a manager, so they suggest that a manager needs to push towards the potential of employees and appreciate them in terms of their performance. It would be also a responsibility of an effective leader to take care genuinely about their concerns and provide tools for personal and professional development [42].

A bad boss is one of the reasons why employees quit their job. A good illustration for this is that boss keeps update information that employees need to succeed. He or she cannot perform his job or accomplish his goals without their help. So, manager shares a critical interdependence with employees. If manager rarely supports them to complete the tasks successfully, they cannot perform well in their assigned responsibilities. In fact, employees will not progress without the information, perspective, experience, and support of manager [43]. Based on a study, it can be argued that the direct and indirect effect of managerial support on turnover cognition represent inconsistency of the reason of manager on turnover intention [44].

\subsection{Training and Development}

Management should initiate to create an environment, where key information has been freely communicated. Employees have the opportunities to be well-informed and insightful for further career development, as well as variety form of training programs will rationally be foremost to an organization. Therefore, this will result in retaining the employees and have a positive impact on the organizational productivity [16].

\subsection{Identifying the Economic Problem}

Generally, employees are most likely to generate the turnover intention due to a variety of economic reasons [45]. This aspect can be attributed to current trade war between the world biggest two economics, the U.S and China. Also, a looming trade tariff America is planning to impose on Mexico if they failed to curb the influx of migrants into the U.S.

\subsection{Job Satisfaction}

The job content and autonomy are the two major job related motivational factors that lead to an increase in employees job satisfaction. Once employees realize that their views are needed in the decision-making process, they could be motivated and desire to do their best for the organization. Shahzad et al. [46], state that "Turnover studies primarily have established that satisfaction with supervision promotes job retention without necessarily identifying specific behaviors by supervisors that commit employees to the company". Experts have identified some factors that are likely to make employees satisfied at work such as good pay, friendly working environment, cooperative colleagues, career counseling and opportunities for training and development [47]. It is also noted that "employees desire managers who realize and treat them fairly" [48]. Unless managers are fair, logical and caring to their employees, it is fairly likely that they will not be happy about their jobs.

\subsection{Unionization}

One of the major advantages of labour unions for organizations are that they lead to less employee's turnover. It is quite probable that employees will not leave their jobs as frequently if they are the members of labour union. One cause for this is that they have to pay dues to be a part of the union, and they typically do not want to lose their position in the organization. Labour unions are organizations in which employees bond together to create a collective voice for negotiations with employers. Previous studies suggest that labour union may be capable to provide safe and better working environment by the negotiations between labour and management, resulting in lower turnover [49].

Another benefit is that labour union by their effective working can improve employee satisfaction. While 
employees deal with unions, they are likely to be more satisfied, as they have a voice to speak to the employer and get higher wages on average and fringe benefits packages. Therefore, labour unions help to reduce the rate of labour turnover, and develop an efficient grievance settlement schemes that will lead to harmonious working environment. Therefore, trade unions contribute to the enhancements in the production level, productivity and discipline, thereby improving on the quality of work life [33].

\subsection{Organizational Culture}

A well-developed organizational culture is a key factor that influences employees to stay put in the organization. If employees are not being contented with the culture, work environment, organizational structure, the probability is that they will quit the job [50]. It is often said that organizations are able to attract and motivate employees by practicing the best organizational culture. Thus, it may lead them to continue work in the organizations.

\subsection{Balancing Work and Family Life}

There can be avoided various retention problems if the organization finds a solution to help employees to effectively control their commitment at home and at work [51]. It is also probable that parents are supposed to take responsibilities, while this comes up to the caring for the family. If we take an example, parents may help to bring back children from school. The study also suggests that flexible working hour can lead to deal with a better work-life balance and, by doing so, can counteract job stress [52]. Hence, managers should be provided the flexible working hour opportunities for their employees.

\section{Conclusion}

Senior management of any organizations should always investigate the causes why valuable employees leave their jobs, and identify issues that motivate and allow them to stay. Job satisfaction is the key determinant factor of employee turnover in an organization. Hence, if a sound strategies are applied, there will be a possibility of the organization to continue flourish in a competitive globalize environment taking into account of the valuable workforce as a vital resource.

Many experts are of the view that employees are the staying power of any organization, so organizations are compelled to take initiative to implement the employees' motivational process, thereby enhancing the overall employees' performance by providing quality products and offering excellent services. The study reveal that about $35 \%$ of the workforce wishes to leave their jobs in higher educational institutions, which likely occur as a result in employee turnover if mitigating strategies are not put in place. It is less expensive to retain the employees than to recruit, train and place new ones.

Therefore, every organizations need to prioritize strategic measures to fill employee vacancies, and develop a robust employee retention strategies to prevent further employees leaving. As a consequence, the motivating factor of the research is to unearth effective and efficient strategies to present a general viewpoint of what the organization requires to identify and anticipate, as well as what are the diverse key strategies available for future reflection in dealing with major issues relating to employee retention.

\section{Recommendation}

The authors were able to make the following recommendations:

1. That all educational institutions within Sierra Leone should establish a Human Resource Department that will work with the Appointment and Promotion Committee to recruit valuable and committed staff. This department would be answerable to the Senate or Board of Trustee.

2. All employee's duties should be clearly stated in their appointment letters, and penalties should clearly state for any employee holding such rules.

3. All employees should strictly follow the line management instituted by top management.

4. Too many meetings should be avoided to allow the staff to complete their duties as per semester.

5. All top managements (directors, deans and HODs) should be assigned to individual office space. This will minimize gossiping and conflicts among employees.

6. That an employee can only be fired or terminated provided that such decision has been approved by the Senate or Board of Trustee via the Registrar, with at least three warming letters.

7. That the institution should identify valuable and talented employee, and retain them on long term for organizational cultural continuity. Losing such valuable employees who the organization invest huge money on them is a total waste.

8. That educational institution should view academic research as a vital tool to unearth new innovations that will drive the organization to a success.

9. The HR Department should conduct appraisal system on a genuine basis and forward those results to the Senate or Board of Trustee that will be used for promotion, transfer, training, demotion, termination, incentive, reward and others.

10. Incentives, rewards, bonuses and allowances, and other motivational tips should be attached to valuable and hardworking employees.

11. Management should also ensure that the working environment is peaceful and should not allow any division among the employees.

12. Staff should not affiliate themselves to students' cultism or social groups.

13. There should be a staff welfare association that will combat injustice from the employer and more especially, staff of such institution should be part of the 
national labour union.

14. A formidable alumni group should be established to cater for the old students who are staff of those institutions.

\section{Acknowledgements}

The authors acknowledges the supports of the Chairman and Secretary, Board of Trustees, Prof. Paul Abass Kamara and Dr. (Mrs.) Abie Paula Kamara respectively at the Institute of Advanced Management and Technology (IAMTECH). The authors further appreciate the effort of the Chief Executive Officer (CEO), Prof. Roseline Umeh Uyanga of IAMTECH for her relentless administrative prowess to attain the "Autonomous University Status" in due course. Special appreciation goes to the Director of research at the Fourah Bay College (USL), Prof. Prince Sorie Conteh, and the Vice chancellor and Principal at the Ernest Bai Koroma University of Science and Technology, Prof. Edwin J. J. Momoh for promoting academic research in the country.

\section{References}

[1] Coff, R. W., (1997), "Human Assets and Management Di lemmas: Coping with Hazards on the Road to ResourceBased Theory", Academy of Management Journal, Vol. 22, pp. 374-402.

[2] Cappelli, P. (2001), A market-driven approach to retaining talent, Harvard Business Review on Finding and Keeping the Best People, Harvard Business School Press, Boston, MA, pp. 27-50.

[3] Cole, C. L. (2000). Building loyalty in Workforce, 42-47.

[4] Maguire, S. (1995). Learning to change. European quality. 2 (8): 23-28.

[5] Annand, K. N. (1997). Give success a chance. Quality progress. pp: 63-64.

[6] Walker J. W. (2001), Human Resource Planning, Vol. 24 No. 1 , pp. 68 .

[7] Aliya Ahmad and Shadab Fariduddin (2003). The motivation to work, Journal of business and organization development.

[8] Kehr, H. M. (2004). Integrating implicit motives, explicit motives, and perceived abilities. The compensatory model of work motivation and volition. Academy of management review.

[9] Eisenberger, R. F.-L. (1990). Perceived organizational support and employee diligence, commitment, and innovation. Journal of applied psychology, 75, 51-59.

[10] Greenhaus, J. H. and G. A. Callanan (1994). Career Management. The Dryden Press, Fort Worth, Texas.

[11] Roepke, R., Agarwal, R., et al. (2000). Aligning the IT Human Resource with Business Vision: The Leadership Initiative at 3M. MIS Quarterly 24 (2): 327-353.

[12] Golden, T. D., Veiga, J. F. (2008). The impact of superiorsubordinate relationships on the commitment, job satisfaction, and performance of virtual workers. Leadersh. Q., 19: 77-88.

[13] Smith, B. D. (2005). Job retention in child welfare: Effects of perceived organizational support, supervisor support, and intrinsic job value Children and Youth Services Rev., 27: 153169.

[14] Khatri, N., Fern, C. T. \& Budhwar, P. (2001). Explaining Employee Turnover in an Asian Context, Human Resource Management Journal, 11 (1), pp. 54-74.

[15] Lambert, E. G., Hogan, N. \& Barton, S. M. (2001). The impact of job satisfaction on turnover intent: a test of a structural assessment model sample of workers, The Social Science Journal, 38 (02), pp. 233-250.

[16] Singh, B. D. (2008). Industrial Relations: Emerging Paradigms. New Delhi: Naraina.

[17] Shaw, J. D., Delery, J. E., Jenkins, G. D. \& Gupta, N. (1998). An Organization-level Analysis of Voluntary and Involuntary Turnover, Academy of Management Review, 41 (5), pp. 511-525.

[18] Labov, B. (1997). Inspiring employees the easy way, Incentive, 171 (10), pp. 114-118.

[19] Dobbs, K. (2001). Knowing how to keep your best and your brightest. Workforce, 21 (4), pp. 57-60.

[20] Alexander, J., Bloom, J. and Nichols, B. (1994). Nursing turnover and hospital efficiency: an organization-level analysis. Industrial Relations, 33 (4), pp. 505-520.

[21] Weiss, H. M., \& Cropanzano, R. (1996). Affective Events Theory: A Theoretical Discussion of the Structure, Causes and Consequences of Affective Experiences at Work. Research in Organizational Behaviour, 8, pp. 1-74.

[22] Lee, T. W., \& Mitchell, T. R. (1994). An alternative approach: The unfolding model of voluntary employee turnover, Academy of Management Review, 19, pp. 51-89.

[23] Labov, B. (1997). Inspiring employees the easy way, Incentive, 171 (10), pp. 114-118.

[24] Ting, Y. (1997). Determinants of job satisfaction of federal government employees. Public Personnel Management, 26, pp. 313-334.

[25] House, R. J., Shane, S. A. and Herold, D. M. (1996). Rumours of the Death of Dispositional research are Vastly exaggerated. Academy of Management Review, 21, pp. 203-224.

[26] Magner, N., Welker, R. \& Johnson, G. (1996). The interactive effects of participation and outcome favorability in performance appraisal on turnover intentions and evaluations of supervisors. Journal of Occupational and Organizational Psychology, 69, pp. 135-143.

[27] Campion, S. M. A. (1991). Meaning and Measurement in Turnover: Comparison of Alternative Measures and Recommendations for Research. Journal of Applied Psychology, 76, pp. 199-212.

[28] O’Reilly, C. A., Chatman, J. \& Caldwell, D. F. (1991). People and organizational culture. A profile comparison approach to assessing person-organization fir, Academy of Management Journal, 34, pp. 487-516.

[29] Thompson, A. A., Strickland, A. J. \& Gamble, J. E. (2006). Crafting and Executing Strategy. The Quest for Competitive Advantage Concepts and Cases. Boston: McGraw-Hill Irwin. 
[30] Luthans, F. (1995). Organizational Behavior. $7^{\text {th }}$ ed. New York, McGraw-Hill.

[31] Carsten, J. M., \& Spector, P. E. (1987). Unemployment, job satisfaction, and employee turnover: A meta-analysis test of the Muchinsky model. Journal of Applied Psychology, 72, pp. 374-381.

[32] Cotton, J. L., \& Tuttle, J. F. (1986). Employee turnover: A meta-analysis and review with implications for research, Academy of Management Review, 11 (1), pp. 55-70.

[33] Martin, R. and Martin, A. C. (2003). Employment Relations in Central and Eastern Europe in 2002: Towards EU Accession, Industrial Relations Journal, 34, pp. 498-509.

[34] Staw, B. M., Bell, N. E. \& Clausen, J. A. (1986). The Dispositional Approach to Job Attitudes: A Lifetime Longitudinal Test. Administrative Science Quarterly, 31, pp. 56-77.

[35] Hulin, C. L., Roznowski, M. \&Hachiya, D. (1985). Alternative opportunities and withdrawal decisions: Empirical and theoretical discrepancies and integration, Psychological Bulletin, 97, pp. 233-250.

[36] Steel, R. P., \& Ovalle, N. K. (1984). A review and metaanalysis of research on the relationship between behavioral intentions and employee turnover. Journal of Applied Psychology, 69, pp. 673-686.

[37] Schervish, P. G. (1983). The structural Determinants of unemployment, Vulnerability and power in market relations. New York, NY: Academic Press.

[38] Mobley, W. H. (1982). Employee Turnover, Causes, Consequences and Control. MA: Addison-Wesley.

[39] Mobley, W. H. (1977). Intermediate linkages in the relationship between job and satisfaction and employee turnover. Journal of Applied Psychology, 62, pp. 237-240.

[40] Porter, L. W. \& Steers, R. M. (1973). Organizational, work, and personal factors in employee turnover and absenteeism, Psychological Bulletin, 80, pp. 151-176.

[41] Guion, R. M. \& Gottier, R. F. (1965). Validity of Personality Measures in Personnel Selection. Personnel Psychology, 8, pp. 135-164.
[42] Maertz, C. P. \& Griffeth, R. W. (2004). Eight motivational forces \& voluntary turnover: A theoretical synthesis with implications for research. Journal of Management, 30 (5), pp. 667-683.

[43] 1Maertz, C. P., Griffeth, R. W., Campbell, N. S., Allen, D. G. (2007). The effects of perceived organizational support and perceived supervisor support on employee turnover. Journal of Organizational Behavior, 28, 1059-1075.

[44] Steers, Richard M. and Richard T. Mowday. "Employee Turnover and Post Decision Accommodation Processes" in Research in Organizational Behavior, edited by L. L. Cummings and B. M. Staw, vol. 3, 235-281. Greenwich, Connecticut: JAI Press, 1981.

[45] Shahzad, K., Bashir, S. \& Ramay, M. I. (2008). Impact of HR practices on the perceived performance of University teachers in Pakistan. International Business Review, 4 (2), pp. 110-123.

[46] Sherman, B., \& Snell, A. (1998). Managing Human Resources, incentives and rewards. Ohio: International Publishing.

[47] Dailey, R. C., \& Kirk, D. J. (1992). Distributive and procedural justice as antecedents of job dissatisfaction and intent to turnover, Human Relations, 45 (3), pp. 305-331.

[48] Ferguson, G. H., \& Ferguson, W. F. (1986). Distinguishing Voluntary from Involuntary Nurse Turnover. Nursing management, 17 (12), pp. 43-44.

[49] Mowday, R. T., Koberg, C. S. \& McArthur, A. W. (1982). The psychology of the withdrawal process: A crossvalidation test of Mobley's intermediate linkages model of turnover in two samples. Academy of Management Journal, 27, pp. 79-94.

[50] Tser-Yieth, C., Pao-Long, C., \& Ching-Wen, Y. (2004). A study of career needs, career development programs, job satisfaction and the turnover intentions of research and development personnel, Career Development International, 9 (4), pp. 424-437.

[51] Boxall, P., \& Purcell, J. (2003). Strategy and Human Resource Management. New York, Palgrave.

[52] 7 Vital Employee Retention Strategies: https://www.forbes.com/sites/billconerly/2013/12/11/quitsare-up-7-employee-retention-strategies-your-company-musthave/\#7d3fb6f97ed4. 